\title{
Sexual Behaviour and Domestic Violence among Teenage Girls in Yakurr Local Government Area, Cross River State, Nigeria
}

\author{
Isokon Brown Egbe ${ }^{1}$ \\ Onyema Okwu Augustina ${ }^{2}$ \\ Ede Victor Itita ${ }^{1}$ \\ Archibong Esther Patrick ${ }^{1}$ \\ Obeten Ude Bassey ${ }^{1}$ \\ ${ }^{1}$ Department of Social Work, University of Calabar, Calabar, Nigeria \\ ${ }^{2}$ Department of Sociology, University of Calabar, Calabar, Nigeria
}

Doi: 10.36941/ajis-2020-0027

\section{Abstract}

The study investigates the relationship between sexual behavior and domestic violence among teenage girls in Yakurr Local Government Area, Cross River State, Nigeria. The study used one research objective and hypothesis to guide the study. Literature was reviewed in accordance with the research variables. Population of the study was basically teenage girls, between ages 13-17 years from the study area. The research instrument used to elicit information from respondents was the questionnaire. The study adopted a survey research design while a sample of 215 respondents was randomly sampled from thirteen council wards that constitute Yakurr. Stratified and simple random sampling technique were adopted. The Pearson product moment correlation analysis was used to test research hypothesis. The results revealed that there is high rate of sexual immorality including premarital sex, illicit sex, rape and homosexuality among teenage girls, leading to high rate of teenage pregnancy, rampant school drop-out and restiveness. Based on these findings, it was recommended that social work intervention measures such as counseling, awareness creation, sensitization, behavioral change process and vigorous campaigns should be organized for teenage girls in the area, so that they would be aware of the dangers of immoral sexual behavior and to avoid the consequences that attend it. Besides, sex education should be vigorously embarked upon to effect behavior modification among the teen girls.

Keywords: Sexual-behavior, Sexual-immorality, Premarital-Sex, Teenage-pregnancy, Domestic-violence, Restiveness

\section{Introduction}

The rate at which teenage girls indulge in immoral sexual behaviors is alarming. According to Hosin (2007) Immoral sexual behavior is pervasive among all strata of society, races, religions, and socioeconomic groups, rural and urban settings. Sexual behavior among teenage girls sometimes manifests in sexy appearance or inappropriate dressing, subservient to pornography, subjection to all forms of sexual feelings, premarital sex, prostitution and other sexy fashionable habits. For what seems to be sexual pleasures or escapades among these young girls, the worst outcome can better be imagined. 
The patterns of societal response to immoral sexual behaviour among teens appears in different forms and diverse circumstances. While in some cultures and society, it may be tolerated in others it is attended with zero tolerance. In a traditional African setting, sexual immorality is a taboo and those involved experience social, physical or emotional deprivation, lack of care, love or empathic attention and stigma. In many occasions, sexual behavior has resulted to family hostility in terms of beatings, terrorizing, rejections, insults, harassment and other abuses. Other forms of domestic violence associated with sexual immorality include emotional trauma, rejection from parents, depression and features of Borderline Personality Disorder (BPD), and degradation, most especially when unwanted or teenage pregnancy is involved (Allen, 2013). The prevalence of single parenthood with all its torments, school drop-out, unwanted pregnancies, and rape are some of the resultant consequences of immoral sexual behavior. More so, some teenage girls become infected with venerable diseases such as HIV/AIDS, syphilis and gonorrhea. Some even meet with untimely deaths. Again, most teens who indulge in illicit sex life combine it with substance abuse by way of taking hard drugs like alcohol, Marijuana and Cocaine which invariably induces them into active premarital sex. These sexual behavior no doubt have adverse effect not only on the individual but on the entire family and society. This study therefore examines some of the domestic violence teenage girls suffer from as a result of their sexual life.

\subsection{Objective of the study}

To determine the extent to which immoral sexual behavior is related to domestic violence among teens in Yakurr Local Government Area of Cross River State, Nigeria.

\subsection{Research questions}

To what extent does immoral sexual behavior relate to domestic violence among teens in Yakurr. Local Government Area of Cross River State, Nigeria?

\subsection{Research hypothesis}

There is no significant relationship between immoral sexual behavior and domestic violence among teens in Yakurr Local Government Area of Cross River State, Nigeria.

\section{Literature Review}

\subsection{Concept of sexual behavior}

Sexuality behaviour tend to differ from one culture to another. For instance, some cultures may condone certain sexual behaviours as acceptable norm, while other cultures may consider same sexual behavior as superfluous or abominable. According to Fasida (2009) factors such as access to sex education, availability and affordability of contraceptive, cultural, religious, societal pressures factors influences sexual behavior. Kost, Henshaw \& Carlin (2010) opined that the risks and challenges teenagers face as a result of their sexual behavior may differ depending on the environment, age, sex and other personal factors. The risks associated with the sexual behavior of teenagers between the ages of 15 and 19, are usually linked more with socio-economic factors than with biological effects of age (Holster, 2011). Also, Shehi (2013) noted that in developing countries, teenagers sexuality behavior are mostly influenced by social issues, such as lower educational levels, higher rates of poverty, poorer life outcomes in teenage parents. In time past, teenage sexuality (ie sex outside marriage) in many communities and cultures in Africa and in most developing countries is usually a taboo.

The rate of sexual immorality and teenage pregnancies tend to be highest in the United States, 
followed by the United Kingdom but lowest in Japan and South Korea (Locoh, 2010). In reporting teenage sexual behaviour rates, Iafus (2011) stated that the number of teenagers (aged 15 to 19) involved in sexual activity before marriage is generally high. Some of the reasons advanced for the high rate of sexual immorality include peer group pressures, high rate of teenage population (Imamba \& Strenisdra, 2010). In societies where gender roles are defined by patriarchal structures, sexual immorality tend to be low (Awafung, 2010). But societies where early sexual activity is condoned, the rate of sexual immorality becomes high. Lack of education and safe sex has also been identified as another cause of high rate of sexual immorality. Treffers (2013) assert that many teenagers lack the knowledge of contraceptive use and sex education.

The increased sexual activity among teenagers is manifested in increased teenage pregnancies and increase in sexually transmitted diseases. The fact also remains that sexual activity among teenagers are common in most countries and cultures of the world and therefore the tendencies to also experience higher levels of domestic violence (Onyema \& Isokon). In an attempt to reverse the increasing illicit sexual behavior among teenagers, sex education programmes were introduced. Abalkhail (2015) found that 13 million young girls under age 20 suffer one form of domestic violence or the other worldwide annually. Out of this number, more than 90 per cent occur in developing countries. He added that domestic violence may lead to teenage pregnancy, complications in pregnancies, and early marriages.

\subsection{Forms of domestic violence associated with immoral sexual behaviors}

In developed regions, such as North America and Western Europe, even though the indulgence of teens in immoral sexual behavior is high, especially because sex is seen as a social issue the rate of teenage pregnancies tend to be low due to the knowledge and utilization of contraceptives and other family planning methods (James \& Nashy, 2015). In contrast, the rate of teenage pregnancies in developing countries is high as most of the pregnancies may be welcomed by family and society and more because of the low level of knowledge and utilization of contraceptives.

Kohler, Manhart \& Lafferty (2008) reported that in the United States of America, more than six in 10 teenage girls, between the ages of 15-19 years have had abortions. However, among the developed nations, the United Kingdom has one of the highest rates of abortions (Hatt, 2013). This was even when it moved down from 27.9 per cent in 2011 to 26.4 per cent in 2016. In his study, Treffers (2013) reported that young teenage girls in Britain admitted having committed abortions while still in school; 8o per cent said they did abortions after they had left school. Treffers (2013) stated that in the Asian continent, abortion is uncommon. Treffers (2013) further noted that the high rate of abortions among teenage girls sometimes means immoral sexual behavior and that the rate of abortions is higher in urban areas than in rural regions.

Flemming (2010) stated that immoral sexual behavior in an industrialized country can affect one's education. This was because immoral sexual activity may result to teenage pregnancy which in turn may lead to school dropout. Poliah (2010) found that women in the US who gave birth during their teens and completed secondary-level schooling were between 10-12 per cent and those that went up to higher or post-secondary education were between 16-22 per cent. 14-29 per cent waited until age 30. Hawkins (2013) posited that low academic achievers are more likely to be those teens who have already indulged themselves in sexual activity.

Forms of sexual abuse include; sexual assault, sexual victimization, sexual exploitation, sexual misuse, sexual molestation, sexual maltreatment, and sexual harassment and rape (Boland, 2012). In the study by Hopper (2014) it was reported that most teenage girls do not have knowledge of sex and sexual relations, or the social meaning of sexuality and its potential consequences, and this constitutes a grave abuse of their rights.

In a survey by Dey, Korn \& Sax (2016) it was reported that 15.1 percent of women in Arab emirates experienced forced marriages. However, much higher incidence rate $(63 \%)$ of forced marriage has been reported in northern Nigeria. According to Ladebo (2013) 76 per cent of women reported to have been 
the target of forced marriage. In the survey, 65 percent of women reported that they had been forced by their parents to marry men they wouldn't have loved to marry, 42 percent of the respondents reported that they have been the subject of marital violence because of forced marriage.

Basu \& Van (2008) noted that the pursuit of money or wealth has exposed many teenage girls to numerous hazards including sexual harassment. Basu \& Van (2008) further argued that greed for money has pushed many school girls into immoral sexual behaviour with its attendant consequences. Scanlon (2012) opined that most college girls indulge in illicit sex for survival or economic drain and want. Korbin (2013) opined that many teenage girls spent most of their time in prostitution in a bid to earn money which thus affect their performance in schools. They further stressed, that these teenage girls do not only go for their sex hobby during the early mornings but at night and during harsh weather as well as school hours. They added, that these type of female students lack concentration in class work due to fatigue and stress, resulting to low self-esteem, withdrawal syndrome, and oppositional behaviour and learning difficulties.

\section{Research Methodology}

The study area is Yakurr Local Governemnt Area of Cross River State, Nigeria. The research design used in conducting this study was the survey method. The population of the study consisted of all female teens (aged 13-18 years) resident in the study area. Two sampling procedures (stratified and simple random sampling) were used to select the sample for the study. First, the thirteen council wards that constitute Yakurr Local Government Area were arranged in strata. That is, each ward formed a stratum; and since there were thirteen council wards, we then had thirteen strata. To draw the sample population, simple random sampling procedure was adopted. This involves going to each council ward and administering questionnaire to teen girls on the basis of random selection. In other words, the researcher selected the respondents randomly. These categories of teens were given questionnaire to fill. This procedure was applied throughout the thirteen council wards. A total of 215 respondents (teens) participated in the study.

The major instrumentation used for data collection was questionnaire designed. The instrument was drawn on a four point likert scale. Out of two hundred and fifty (250) questionnaires given out, two hundred and fifteen (215) were filled and returned, giving a percentage of 96.o. This is adequate for the study. The hypothesis was stated in the null form, and tested at o5 level of significance, using the independent t-test statistical test.

\section{Results}

$\mathrm{H}_{\mathrm{o}}$ : There is no significant relationship between immoral sexual behavior and domestic violence among teens in Yakurr Local Government Area of Cross River State, Nigeria.

$\mathrm{H}_{1:}$ There is significant relationship between immoral sexual behavior and domestic violence among teens in Yakurr Local Government Area of Cross River State, Nigeria.

In this hypothesis, immoral sexual behavior served as the independent variable while domestic violence among teens served as the dependent variable. The Pearson product moment correlation ( $\mathrm{r}$ ) was used to test the research hypothesis. The result is presented in Table 1.

Table 1: showing analysis of Pearson product moment correlation on the relationship between immoral sexual behavior and domestic violence $(n=215)$

\begin{tabular}{lcccccc}
\hline Variables & Mean & SD & $\Sigma \mathrm{Y}$ & $\Sigma \mathrm{Y}^{2}$ & $\Sigma \mathrm{XY}$ & $\mathrm{R}$ \\
\hline Immoral sexual behavior & 3.88 & 5.85 & 15,659 & 20,760 & 1462673837 & $0.85^{*}$ \\
Domestic violence & 5.13 & 6.19 & 11,001 & 17260 & 1460 \\
\hline
\end{tabular}

*Significant at 0.05 level, critical $\mathrm{r}=0.139, \mathrm{df}=301$ 
Since the calculated r- value of 0.85 is greater than the critical R-value of 0.139 at 0.05 levels of significance with 301 degrees of freedom, the null hypothesis is rejected while the alternate hypothesis is accepted. This result therefore shows that there is significant relationship between immoral sexual behavior and domestic violence among teens in Yakurr Local Government Area of Cross River State, Nigeria.

\section{Discussion of Findings}

The findings of this study reveals that there is significant relationship between immoral sexual behavior and domestic violence among teens in Yakurr Local Government Area of Cross River State, Nigeria. The study supports Warner (2013) who opined that cases of immoral sexual behavior are recently on the sky-rocketing note and it is plunging teenage girls and indeed the society into dire socio-economic and psychological crises. He added that putting a female teenager in the family way means putting more burdens on the family. This is why, according to him, in civilized societies, impregnating a teen receives wide condemnation, accusing culprits as opportunists, insensitive, heartless and having no goodwill to society. The study also supports Mayor (2014) who asserts that the incidence of illicit sex is higher among adolescents worldwide and that those indulge in them are likely to have catastrophic consequences, such as unwanted pregnancy, infectious diseases among others. When this happens, the parents and family sometimes react with hostility and refuse to take responsibility if the girl becomes pregnant outside wedlock.

The study also agrees with Halinma (2011) who opined that teenage sexual behavior have some socioeconomic, medical and psychological impact on families and societies. Some families began to experience poverty, lack of social support, lack of medical care, when any of its female member is pregnant outside wedlock. It also supports Eshrada (2016) who in his survey revealed that complications arising from immoral sexual activities are the leading cause of poverty and psychological trauma among family members.

In Yakurr Local Government Area, some teenage girls went into marriage at their early age and they start bearing children from that early age. The high rate of teenage pregnancy exacts a heavy toll on the family and society. Most pregnant teens are at risk of suffering more health issues; some get addicted to drinking, smoking and drugs due to post pregnant stress; some gain less weight during pregnancy and are at higher risk for premature births, which can also affect low birth weight of the baby. All these give family members a cause for worry, anxiety and even sicknesses.

The study also found that there is high rate of school drop-out due to teens engagement in immoral sexual behavior. This finding supports the study of Shehi (2013) who reported that cases of teenage pregnancy in our society is a social malfunction in the sense that promising teenage girls are compelled to abandon school because of pregnancy, a situation that erode all their dreams. In other words, they are on the path of prematurely terminating their prospects of becoming useful contributing elements to their families and the entire community. The study also is in support of Flemming (2010) who pointed out that pregnant teens who are likely to continue with their education are those who can rely on family and community support, social services and child-care support and those who get higher paying jobs as they progress with their education. An interesting finding in this study is that teens who drop out of school more often than not become disobedient and stubborn to their parents. This further trigger behaviors that brings shame to their parents.

Teenage indulgence in illicit sex creates social problem and is associated with increased rates of poverty to the individual involved and their families. This finding agrees with Ajayi (2009) that while poverty cause most girls to enter into illicit sex, but by the time they become pregnant or contract infectious diseases, severe form of poverty start staring them in the face. Some female teenagers get into illicit sex with "sugar daddies" in a bid to get rich or get benefits and other welfare packages. In the study area most teenage girls were impoverished at the time of being pregnant or faced with other issues related to their sexual behaviors. Nearly all teen mothers have made their family members or parents impoverished especially when the parents are unemployed. Most teenaged 
mothers in the study area are deprived of social and economic opportunities due to becoming pregnant outside wedlock and this denies the family from getting the traditional bride price on their heads.

The study is in agreement with the work of Afe (2011) which reported that 45 per cent of sexual related behavior and activities gave birth to rape. He added that the way and manner some teenage girls appear in the type of dresses they wear creates opportunity for rape. One in five teenage boys admitted to forcing girls to have sex with them. The study further agrees with Ajayi (2009) who stated that most adolescent girls are often in abusive relationships due to their sexual life style. They have also reported that teenage sexual behavior has often intensified violent behaviors on the part of their parents.

In the study area, most teens have experienced domestic violence as a result of their life style concerning sexuality. Evidence from the study has also shown that it is a common practice for teenagers to be beaten by their guardians. Some had experienced attempts of birth control sabotage or work sabotage. Some pregnant teens are exposed to abuse and are more likely to generate family strife. The risk of becoming pregnant as a teenager increases with the increased engagements in sexual experiences. Most families are torn apart and one or two families have become enemies due to rape or sexual molestations of ther children. This is especially the case when a boy from a different family raped a girl from another family. The girl's family will not take it kindly and may want to seek redress in court or take other measures to get justice. Again, some boys impregnate a girl without any intention of marrying her and later abandon her. This in most cases brings about family dysfunction with enduring unfavorable social, psychological and physical consequences for the parents.

\section{Conclusion}

The study gives an insight into the relationship between sexual behavior and domestic violence among teenage girls in Yakurr Local Government Area, Cross River State, Nigeria. Specifically, this study implies that in that relation, the higher rate of illnesses and mortality for pregnant teens, higher rate of school drop-out by pregnant teens, teenage pregnancy, poverty and the higher rate of violence against pregnant teens were domestic violence variables that result from teen's sexual immorality in the study area and therefore needed consideration. There is no gainsaying the fact that the prevalence of sexual promiscuity among teenagers in the study area generates various forms of domestic violence. Beside, sexual freedom is common which implies that the cultural norms which ought to have restrain teenagers from sexual intercourse is weak. The normative culture rather than constrain teenagers from immoral sexual behaviour turn around to promote immoral behaviour. The resultant consequence being cases of early marriage, high rate of teenage pregnancies.it was also observed that so many teenagers become mothers even they are not married. Some of them, especially the female ones die quite early while trying to abort unwanted pregnancies. Some of them contact dreaded diseases such as HIV/AIDS while some are frustrated out of school caused by their negative sexual behaviors. On the whole, not only does it affect the teenagers but also their families and the society in general. This is evident in the social, psychological and economic burden placed on parents to meet the needs of these ones.

\section{Recommendations}

1. Teenagers should cultivate the practice that will sustain their future by abstaining from illicit sex which destroys their future.

2. Parents should also fulfill their parental responsibilities by ensuring that their activities cause minimal harm to the child, and they have the duty to protect, guide and direct their children and wards properly.

3. The government should periodically organize awareness campaigns and sensitization programmes for teenagers in the area. The purpose is to educate and inform teenagers on 
the dangers of illicit sex and teenage pregnancy not only to human health but also as it is capable of thwarting their future

4. Educational institutions and churches in the study area should embark on comprehensive sex education. This will help to effectively reduce the rate of sexual activities among teens in the area.

5. The government should create a learning environment in which all teenagers will be occupied at all times in meaningful ventures. These should include the provision of sporting equipment, skill acquisition and entrepreneurship programmes.

\section{References}

Abalkhail, B. A. (2015). Adolescent Pregnancy: Are there biological barriers for pregnancy outcomes? The Journal of the Egyptian Public Health Association. 70 (5-6), 609-25.

Afe, J. (2011). Brief motivational intervention at a visit reduces promiscuity among school girls. School Instructor. 77(1) $49-59$.

Ajayi, R. (2009). The family: boy-girl relationship: sex abuse from the family perspective. Washington, D. C. Technical Report Series NO. 5/6 on Youth and Drugs.

Allen, C. (2013). Peer pressure and teen sex. Psychology Today. 5 (3) 67-89.

Awafung, W. (2010). Understanding sexual behavior among teenage girls. Post Graduate Medicine. Unpublished Material. University of Calabar, Calabar.

Basu, K. \& Van, P. (2008). The economics of sexual behaviors and child labour. American Economic Review, 88(3), $412-427$.

Boland, M. L. (2012). Sexual harassment: Your guide to legal action. Naperville Illinois: Sphinx publishing.

Dey, E. L., Korn, J. S. \& Sax, L. J. (2016). Betrayed by the academic. The sexual harassment of women. Journal of Higher Education, $67(2)$, 149-173.

Eshrada, L. (2016). Pregnancies are the sum of births, abortions and miscarriages. Http://Www.Pubmedcentral.Nih.Gov/Articlerender.Fcgi.Tool=PmcentrezandCartid=411126.

Fasida, M. (2009). Adolescents in changing times: issues and perspectives for adolescent reproductive health in the ESCAP.Guttmacher.Org.Guttmacer.Org.

Flemming, O. (2010). The nature and patterns of problems for secondary school counseling. The Counselor (1) 23867.

Halinma, J. (2011). US teenage pregnancy rate drops for $10^{\text {th }}$ straight year. Journal of Health Issues and Development. 46(7), 34-47.

Hatt, O. (2013). Some factors responsible for juvenile delinquency among Nigerian youths. The Educator 2(1), 6071.

Hawkins, D. (2013). Psychological guidance of the social child. Ibadan: Evans Books.

Holster, C. (2011). Roots of western tradition: a short history of the ancient world. New York: Wiley

Hopper, J. (2014). Child abuse statistics, research and resources. Retrieved from http/www.jimhopper.com.

Hosin, A. A. (2007). Responses to traumatized children. Basing stock: Palgrave Macmillan. pg. 211. ISBN: 1-40399680-6.

Iafus, U. S. (2011).Teenage pregnancy statistics: overall trends by race and ethnicity and state-by-state information. New York: The Allan Guthmacher Institute.

Imamba, A. \& Strenisdra, F. (2010).The national campaign to prevent teen pregnancy: not just another single issue: teen pregnancy prevention's link to other critical social issues. PDF $(147 \mathrm{~KB})$. Retrieved February, 2012.

James, H. \& Nashy, U. (2015). Health indicators: facts and statistics. sexual health and Canadian youth: Teen Pregnancy Rates. Http://Www.Unicef-Irc.Org/Cgi-Unicef/Lunga.Sql.Product/Id.

Kohler, P. K, Manhart, L. E. \& Lafferty, W. E. (2008). Abstinence- only and comprehensive sex education and the initiation of sexual activity and teen pregnancy. Journal of Adolescent Health (42)344-351.

Korbin, J. E. (2013). Children, childhoods, and violence. Annual Review of Anthropology, 32, 431446.

Kost, K; Henshaw, S \& Carlin, L. (2010). US teenage pregnancies, births and abortions: national and state trends and trends in race and ethnicity. Http://Www.Guttmacher.Org/Pubs/Ustptrends.Pdf.

Ladebo, O. J. (2013). Sexual harassment in academic in Nigeria. How Real: African Sociological review, 7(1), 35-47.

Locoh, T. (2010). Early marriage: and motherhood in Sub-Saharan Africa. London: WIN News

Mayor, S. (2014). Pregnancy and Childbirth are Leading Cause of Death in Teenage Girls in Developing Countries. BMJ. 328 (7449):1152. 
Onyema, O. A. \& Isokon, B. E. (2017). Mandatory Premarital HIV/AIDS Test and Break Up of Marital Engagement among Intending Couples in Some Pentecostal Churches in Southern Senatorial District of Cross River State, Nigeria. Journal of Sociology and Social Work December 5(2), 118-127.

Poliah, R. A. (2010). Self-esteem theory of sex abuse. Journal of U.S. Pharmacist. 23(10), 57-62

Scanlon, T. (2012). Child labour: Vast problem whose effects on children's health remain largely unstudied. Chicago: Brown Publishers.

Shehi, I. (2013). Interest and discipline in education. London: Unwin Brothers Ltd.

Treffers, P. E. (2013). The teenage pregnancy: A World Wide Problem. NED Tijdschr Geneeskd 147 (47), 2320-5 PMID 14669537.

Warner, J. (2013). The psychology and personality of youth indulgence in sexual activity. Journal of American Family Physician. 46(74), 60-65. 